\title{
A case of Bardet-Biedl syndrome caused by a recurrent variant in BBS12: A case report
}

\author{
INA OFELIA FOCȘA ${ }^{1}$, MAGDALENA BUDIȘTEANU ${ }^{2-4}$, CARMEN BURLOIU ${ }^{2}$, SHERAZ KHAN ${ }^{5,6}$, \\ AZITA SADEGHPOUR $^{7,8}$, LAURENȚIU C. BOHÎLȚEA $^{1}$, ERICA E. DAVIS ${ }^{6,9}$ and MIHAELA BĂLGRĂDEAN ${ }^{10,11}$ \\ ${ }^{1}$ Department of Medical Genetics, University of Medicine and Pharmacy 'Carol Davila', 021901 Bucharest; \\ ${ }^{2}$ Department of Pediatric Neurology, 'Prof. Dr. Alexandru Obregia' Clinical Hospital of Psychiatry, 041914 Bucharest; \\ ${ }^{3}$ Medical Genetic Laboratory, 'Victor Babeș’ National Institute of Pathology, 050096 Bucharest; \\ ${ }^{4}$ Department of Medical Genetics, Titu Maiorescu University, 040441 Bucharest, Romania; \\ ${ }^{5}$ National Institute for Biotechnology and Genetic Engineering (NIBGE-C), Faisalabad, \\ Pakistan Institute of Engineering and Applied Sciences, Islamabad 38000, Pakistan; \\ ${ }^{6}$ Advanced Center for Translational and Genetic Medicine, Stanley Manne Children's Research Institute, \\ Ann and Robert H. Lurie Children's Hospital of Chicago, Chicago, IL 60611; \\ ${ }^{7}$ Center for Human Disease Modeling, Duke University Medical Center, Durham, NC 27701; \\ ${ }^{8}$ Duke Center for Applied Genomics and Precision Medicine, Duke University, Durham, NC 27708; \\ ${ }^{9}$ Departments of Pediatrics and Cell and Developmental Biology, Feinberg School of Medicine, \\ Northwestern University, Chicago, IL 60611, USA; ${ }^{10}$ Department of Pediatrics and Pediatric Nephrology, \\ Emergency Clinical Hospital for Children 'Maria Skłodowska Curie'; ${ }^{11}$ Department of Pediatrics, \\ University of Medicine and Pharmacy 'Carol Davila', 077120 Bucharest, Romania
}

Received August 3, 2021; Accepted September 29, 2021

DOI: $10.3892 / b r .2021 .1479$

\begin{abstract}
Bardet-Biedl syndrome (BBS) is a clinically and genetically heterogenous disorder that manifests as a result of primary cilia impairment. Cilia are present on most cell types, thus BBS is a multisystemic condition involving the majority of organ systems. The core features of the syndrome include retinal degeneration, obesity, polydactyly, cognitive impairment, renal anomalies and urogenital malformations. To date, pathogenic variants in 26 genes have been shown to be involved in the molecular basis of this rare ciliopathy. Of these causal loci, $B B S 12$ accounts for $\sim 8 \%$ of all cases. In this case report, an individual with BBS caused by a rare recurrent variant in BBS12 (NM_152618.3: c.1063C>T; p.Arg355*) is described and compared with others with the same DNA variant, placing this finding in the context of the current literature.
\end{abstract}

Correspondence to: Dr Erica E. Davis, Advanced Center for Translational and Genetic Medicine, Stanley Manne Children's Research Institute, Ann and Robert H. Lurie Children's Hospital of Chicago, 225 E. Chicago Avenue, Box 205, Chicago, IL 60611, USA E-mail: eridavis@luriechildrens.org

Key words: Bardet-Biedl syndrome, cilia, ciliopathies, chaperonin, oligogenic, pleiotropy

\section{Introduction}

Bardet-Biedl syndrome (BBS) [Mendelian Inheritance in Man (MIM), 209900] is a heterogenous disorder that is caused by the impairment of primary cilia. It belongs to a broad group of disorders known as ciliopathies, and represents a hallmark exemplar with a highly variable clinical presentation, likely due to second-site modification of primary causal loci (1-3). The predominant clinical features associated with BBS are retinal degeneration, obesity, polydactyly, cognitive impairment, renal disease and hypogonadism or urogenital malformations. Minor symptoms that may complicate a clinical diagnosis of BBS include developmental delay, behavioral and psychiatric abnormalities, metabolic and endocrine impairment, cardiovascular involvement, liver disease, Hirschsprung disease and olfactory deficits (4). Given the wide phenotypic variability that exists within and amongst BBS families, a clinical diagnosis of BBS may prove to be challenging. However, a diagnostic algorithm has been proposed by the presence of either four major features, or three major features and two minor symptoms (5). Moreover, it is difficult to make an accurate early diagnosis since the majority of the symptoms may only occur over time. Therefore, the median age of diagnosis is 9 years of age, and typically the diagnosis is associated with the occurrence of retinal degeneration $(5,6)$. Although certain symptoms can be detected at an antenatal stage, such as polydactyly or genitourinary abnormalities, in the absence of a positive family history and established molecular underpinnings, such a diagnosis is rarely established in early childhood (7). Obesity, which is 
Table I. Causal Bardet-Biedl syndrome genes.

\begin{tabular}{|c|c|c|c|c|c|}
\hline Gene no. & Gene name & Alias & MIM number & $\begin{array}{l}\text { Chromosomal } \\
\text { location }\end{array}$ & $\begin{array}{l}\text { Subcellular location } \\
\text { of related proteins }\end{array}$ \\
\hline 1 & $B B S 1$ & & 209901 & $11 \mathrm{q} 13.2$ & BBSome \\
\hline 2 & $B B S 2$ & RP74 & 606151 & $16 \mathrm{q} 13$ & BBSome \\
\hline 3 & $A R L 6$ & BBS3, RP55 & 608845 & $3 q 11.2$ & BBSome associated \\
\hline 4 & $B B S 4$ & & 600374 & $15 \mathrm{q} 24.1$ & BBSome \\
\hline 5 & BBS5 & & 603650 & $2 \mathrm{q} 31.1$ & BBSome \\
\hline 6 & $M K K S$ & HMCS, KMS, MKS, BBS6 & 604896 & $20 \mathrm{p} 12.2$ & Chaperonin complex \\
\hline 7 & $B B S 7$ & & 607590 & $4 \mathrm{q} 27$ & BBSome \\
\hline 8 & TTC8 & BBS8, RP51 & 608132 & $14 q 31.3$ & BBSome \\
\hline 9 & PTHBI & BBS9 & 607968 & $7 \mathrm{p} 14.3$ & BBSome \\
\hline 10 & $B B S 10$ & C12orf58, FLJ23560 & 610148 & $12 \mathrm{q} 21.2$ & Chaperonin complex \\
\hline 11 & TRIM32 & HT2A, LGMDR8, BBS11 & 602290 & $9 \mathrm{q} 33.1$ & Cilium base \\
\hline 12 & BBS12 & FLJ35630, C4orf24 & 610683 & $4 q 27$ & Chaperonin complex \\
\hline 13 & $M K S 1$ & MKS, BBS13, JBTS28 & 609883 & $17 q 22$ & Basal body \\
\hline 14 & CEP290 & $\begin{array}{l}\text { KIAA03733H11AG, JBTS5, SLSN6, } \\
\text { LCA10, BBS14 }\end{array}$ & 610142 & $12 \mathrm{q} 21.32$ & Basal body \\
\hline 15 & $W D P C P$ & C2orf86, BBS15, CHDTHP & 613580 & $2 \mathrm{p} 15$ & Basal body \\
\hline 16 & SDCCAG8 & CCCAP, SLSN7, BBS16 & 613524 & $1 q 43-q 44$ & Basal body \\
\hline 17 & LZTFL1 & BBS17 & 606568 & $3 \mathrm{p} 21.31$ & BBSome associated \\
\hline 18 & $B B I P 1$ & NCRNA00081, BBIP10, BBS18 & 613605 & $10 \mathrm{q} 25.2$ & BBSome \\
\hline 19 & IFT27 & RABL4, BBS19 & 615870 & $22 q 12.3$ & IFT \\
\hline 20 & IFT74 & CCDC2, CMG1 & 608040 & $9 \mathrm{p} 21.2$ & IFT \\
\hline 21 & CFAP418 & C8orf37, CORD16, RP64, BBS21 & 614477 & $8 \mathrm{q} 22.1$ & Cilium base \\
\hline 22 & $N P H P 1$ & & 607100 & $2 q 13$ & Transition zone \\
\hline 23 & IFT172 & & 607386 & $2 \mathrm{p} 23.3$ & IFT \\
\hline 24 & SCAPER & & 618195 & $15 \mathrm{q} 24.3$ & Cilium tip \\
\hline 25 & SCLT1 & & 611399 & $4 q 28.2$ & Distal appendage \\
\hline 26 & CEP164 & & 614848 & $11 \mathrm{q} 23.3$ & Distal appendage \\
\hline
\end{tabular}

BBS, Bardet-Biedl syndrome; IFT, intraflagellar transport; MIM, Mendelian Inheritance in Man.

noted in $72-92 \%$ of patients with BBS, becomes evident during the first 3 years of life. Typically, the birth weight is normal, and the weight gain commences during the first year $(5,7)$. Obesity is associated with a higher risk of developing diabetes, metabolic syndrome or hypertension $(8,9)$. Cognitive difficulties are common ( $>60 \%$ of individuals with BBS), although only $25 \%$ of those observed fulfill the intellectual disability consensus criteria (10). Some specific deficits, such as perceptual reasoning, attention capacity and functional independence, appear to be the most severely affected (10). Other neuropsychiatric abnormalities have been observed in BBS, including developmental delay, either motor or language impairment, and a broad spectrum of behavioral disturbances, such as emotional instability, disinhibition, aggressiveness, self-injury or obsessive-compulsive behavior (10). Kidney disease affects $53-82 \%$ of patients with BBS, and this represents the common cause of morbidity and mortality (11). The renal phenotype is highly variable, with renal dysfunction leading to end-stage renal failure in $42 \%$ of adult patients, as revealed by a large BBS cohort study (12). Individuals with BBS also display structural anomalies ranging from cysts, fetal lobulation, renal dysplasia, calyceal distortion and hydronephrosis to ectopic, atrophic, horseshoe kidney or renal agenesis $(13,14)$. Hypogonadism and genital anomalies are observed in 59-98\% of patients. Small penile length has also been identified in nearly all males with BBS, whereas hypoplastic labia minora is common in females. Less frequently, hydrometrocolpos may complicate many of the malformations, including vaginal atresia and septate or imperforate vagina, which may be identified antenatally or shortly after birth $(5,11,15)$. In a minority of individuals, valvular stenosis, atrial/ventricular septal defects or cardiomyopathy are observed, which may be diagnosed at the prenatal or neonatal stage $(5,16)$, whereas anosmia, hearing loss, liver disease, Hirschsprung disease and laterality defects have been reported at different ages of onset $(4,17,18)$.

At the time of this report, 26 genes have been associated with the pathogenesis of BBS (Table I). The majority of the encoded BBS proteins localize to the base of the cilium, and all have been shown to be involved in ciliary biogenesis or function (Fig. 1) (11). The BBS1, BBS2, BBS4, BBS5, BBS7, TTC8/BBS8, BBS9 and BBIP1/BBS18 proteins are components of the BBSome, a macromolecular complex 


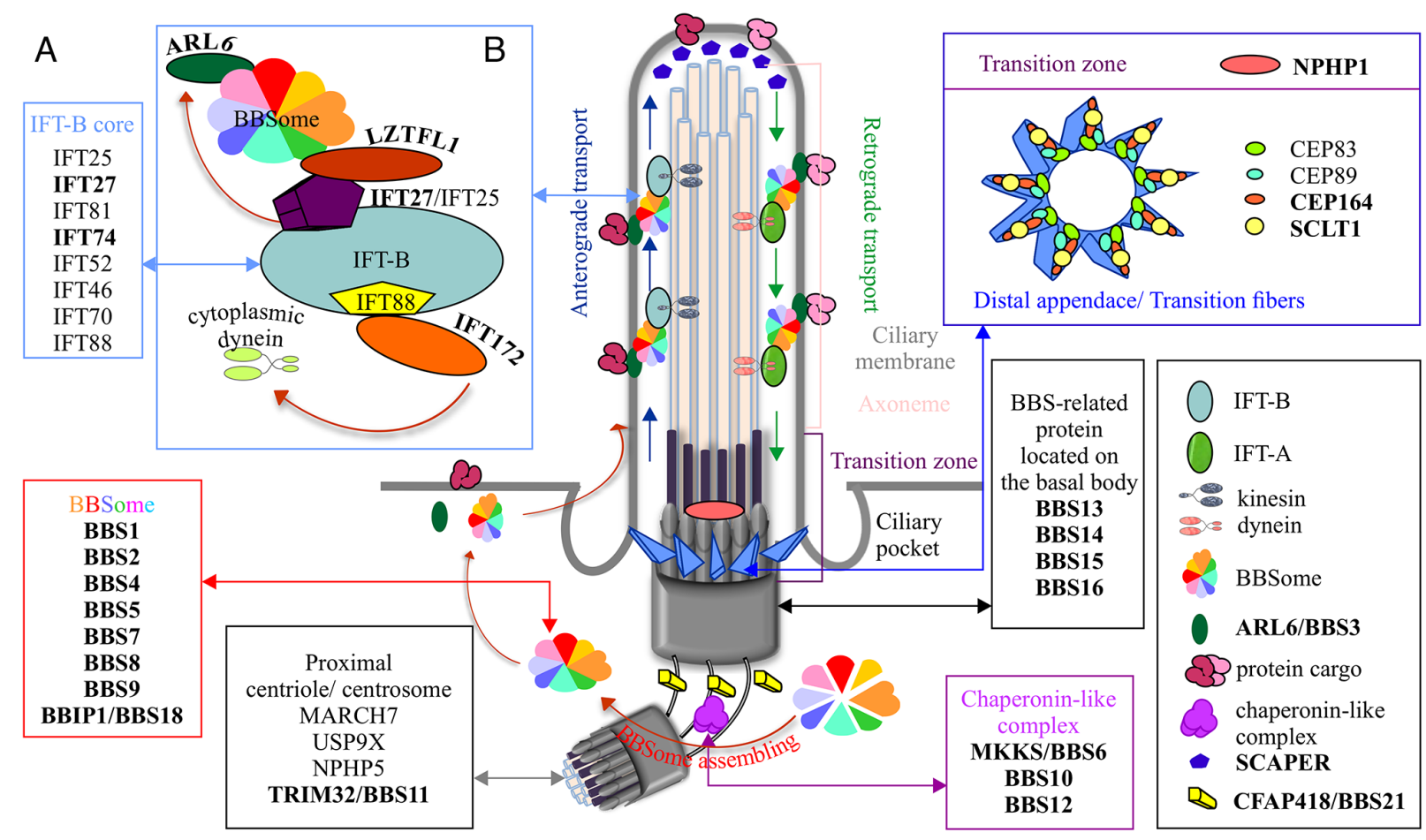

Figure 1. Location and interaction of BBS proteins within cilium. (A) Overview of BBS protein complexes at the cilium. (B) Details of anterograde transport molecule assembly. The BBS proteins are shown in bold. BBS, Bardet-Biedl syndrome.

that functions as an adaptor for intraflagellar transport (IFT) molecules $(19,20)$. IFT molecules undergo bidirectional movement along the microtubule backbone (IFT-A and IFT-B protein complexes), acting as a carrier for proteins involved either in signaling pathways or in ciliary homeostasis (21). IFT27/BBS19, IFT74/BBS20 and IFT172 are components of the IFT-B complex, which confers anterograde IFT (22). IFT27/BBS19 has been suggested to interact with ADP ribosylation factor like GTPase 6 (ARL6)/BBS3, hence modulating the ciliary export of hedgehog signaling molecules. It has also been proposed that IFT27/BBS19 may interface with the BBSome complex through an interaction with leucine zipper transcription factor like 1 (LZTFL1)/BBS17 $(23,24)$. IFT74/BBS20 has been shown to interact with IFT27/BBS19, whereas the remaining IFT-B molecules, including IFT172, play an important role in cilium stability $(25,26)$. The position of the BBSome within the cilium is stabilized by ARL6/BBS3, a small GTPase that recruits the BBSome to ciliary membranes (19). The MKKS centrosomal shuttling protein (MKKS)/BBS6, along with the BBS10 and BBS12 proteins form part of the chaperonin-like complex that has an important role in BBSome assembly $(27,28)$. Several proteins function at the basal body (MKS1/BBS13, CEP290/BBS14, WDPCP/BBS15 and SDCCAG8/BBS16) and are involved in ciliogenesis and the modulation of BBSome trafficking within the ciliary compartment (29-31). Tripartite motif containing 32/BBS11 is an E3 ubiquitin ligase that regulates components of the cytoskeleton, whereas LZTFL1/BBS17 is hypothesized to regulate BBSome activity through transient interaction with BBS9 (32-34). Cilia and flagella associated protein (CFAP)418/BBS21 is located at the base of the cilium, and appears to have a role in facilitating protein transport, although its complete function and mode of interaction within the BBS protein network have yet to be fully elucidated (35). Nephrocystin 1 (NPHP1), localized in the ciliary transition zone, has been shown to regulate the early stage of cilia formation $(31,36)$ Recently associated with BBS, sodium channel and clathrin linker 1 (SCLT1) and centrosomal protein (CEP)164 are components of the distal appendages that are responsible for docking the cilium to the plasma membrane (37-39). Both of these are required for ciliary initiation. Another gene that has recently been shown to be associated with BBS is S-phase cyclin A associated protein in the ER (SCAPER), which was found to localize at the ciliary tip, suggesting that it may be involved in ciliary dynamics during the cell cycle (40). Pathogenic variants in these genes have been identified in $>80 \%$ of patients with BBS, and this percentage has increased rapidly during the past decade due to the extensive use of next-generation sequencing approaches (7). The most common pathogenic variants occur in BBSI and BBS10, accounting for $\sim 45 \%$ of clinically assessed cases. Considered together, the genes that code for components of the BBSome are most frequently (up to 57\%) found mutated in patients with BBS, and these are followed by the group of genes that encode chaperonin-like proteins $(\sim 30 \%)$. Pathogenic variants identified in ARL6/BBS3 account for $\sim 8 \%$ of the clinically diagnosed individuals. The remainder of the BBS genes are rarely found to be causal, and these account for $\sim 5 \%$ of cases; moreover, certain variants found in these genes have been reported in only a few families $(41,42)$. However, the frequency of a specific pathogenic variant appears to be correlated with the ethnic background of the affected individuals. Whereas $B B S 1$ and $B B S 10$ are most frequently impaired amongst individuals of European descent, pathogenic variants in $B B S 4$, $B B S 5$ and $B B S 8$ appear to be enriched in Middle Eastern and North African populations (43-45). Notably, there is a higher 

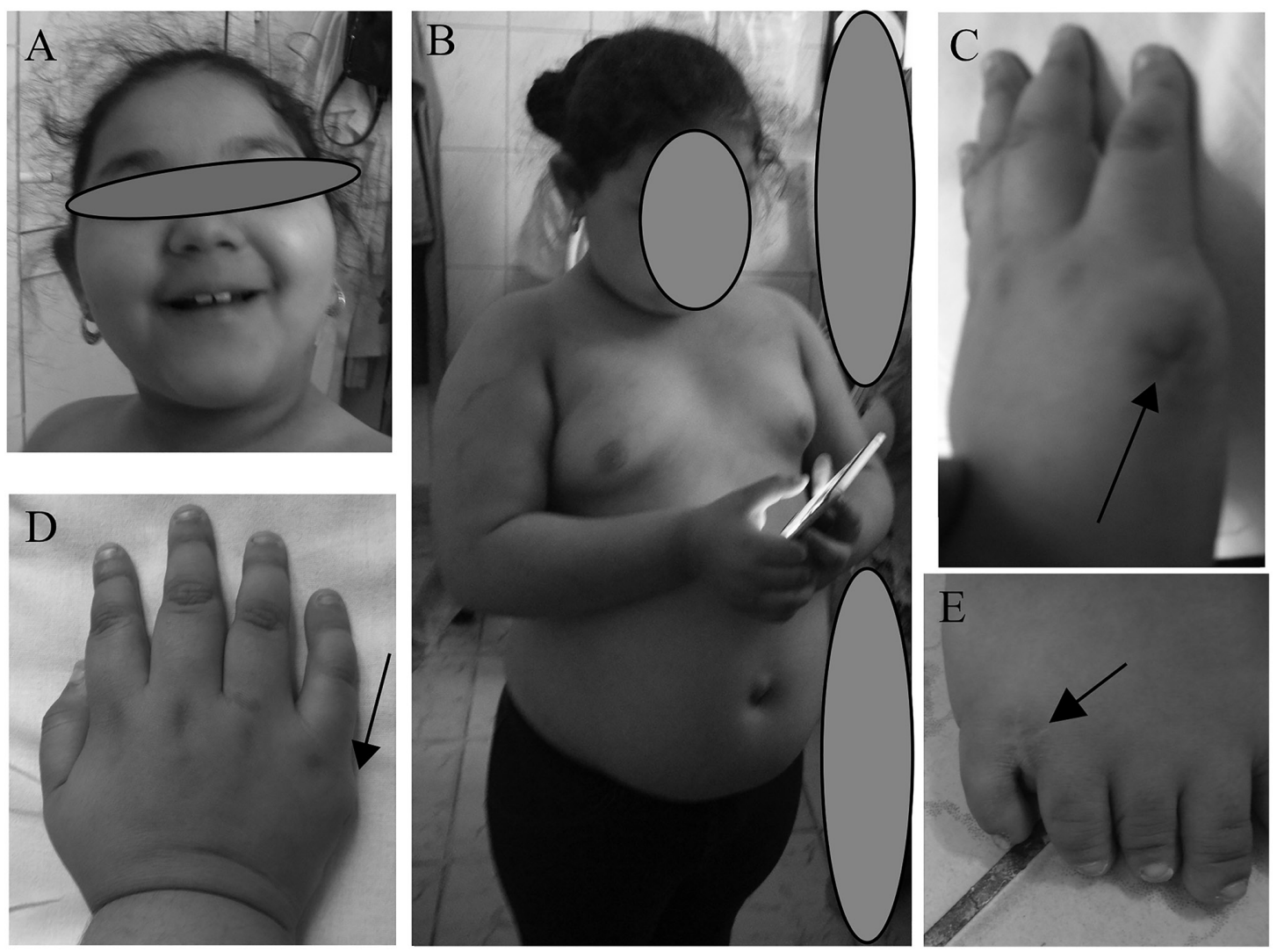

Figure 2. Images of the presented case. Images of the patient at (A-E) 5 and (B) 6 years-old, showing: (A) Tooth anomalies and dysmorphic craniofacial features, such as narrow forehead, decreased bitemporal diameter, sparse eyebrows, long and smooth philtrum and full cheeks; (B) Obesity; (C-E) scars and (C and D) reminiscent bone deformity after removal of polydactyly (black arrows); (D) brachydactyly, conic fingers, hypoplasia of distal phalanges and hypoplastic nails; and (E) partial cutaneous syndactyly of the second and third toes, and hypoplastic nails.

prevalence of $A R L 6 / B B S 3$ pathogenic variants in consanguineous Saudi and Indian families $(46,47)$.

BBS has been shown to be predominantly inherited in an autosomal recessive fashion, although it may also be inherited as an oligogenic trait $(48,49)$. The underlying molecular mechanism is often complicated through the intervention of a third mutant locus, giving rise to 'triallelic inheritance', which may explain the extensive clinical variability of patients with BBS (50). Similarly, it has been hypothesized that the presence of second-site modifier or epistatic interactions are responsible both for intrafamilial or interfamilial clinical heterogeneity and for the severity of the phenotype $(2,51,52)$. Copy number variants and retrotransposon insertions have been proposed to contribute to the pathogenesis of BBS $(53,54)$. Furthermore, it has been suggested that even environmental events may be involved in defining the complexity of the BBS phenotype (55).

Here, a hitherto unreported case of BBS, clinically diagnosed in accordance with consensus criteria established by Beales et al (5), that was caused by a rare recurrent c.1063C $>$ T; p.Arg355* variant in BBS12 is described. The molecular finding was identified by whole exome sequencing (WES) and confirmed by Sanger sequencing.

\section{Case report}

Written informed consent was obtained from the legal guardian of this patient and her family members, and they were all enrolled in the research study approved by Institutional
Review Board of University of Medicine and Pharmacy 'Carol Davila' Bucharest (approval no. 29700, T.42; Oct 01, 2015). Additionally, the present study conformed to the guidelines of the Declaration of Helsinki (56). EDTA-treated peripheral blood samples from willing family members were collected (the patient, the patient's sibling and their parents) subsequent to informed consent. Genomic DNA was extracted from the blood using the PureLink ${ }^{\circledR}$ Genomic DNA Extraction kit (Invitrogen; Thermo Fisher Scientific, Inc.) according to the manufacturer's instructions. WES was performed by the Advanced Center for Translational and Genetic Medicine, Ann \& Robert H. Lurie Children's Hospital of Chicago, IL, USA, according to a research study approved by the Lurie Children's Hospital IRB (approval no. IRB 2019-3057; Aug 5, 2019). WES was performed on proband genomic DNA samples according to an established protocol (LC Sciences, LLC). Fragmented DNA samples generated via sonication were subjected to library construction. Exome capture was performed using an Agilent SureSelect Human All Exon V6 kit (Agilent Technologies, Inc.) according to the manufacturer's instructions, and next generation sequencing was subsequently performed using an Illumina Novaseq6000 system at Lianchuan Bio for a 150 bp paired-end run, to a mean target depth of 147X, generating a total of 74,060,974 paired-end reads.

For bioinformatics analysis, and prior to alignment, low-quality reads (first, reads containing sequencing adaptors, and secondly, nucleotides with a quality score $<20$ ) were removed to yield a total of $73,150,226$ cleaned paired-end reads. The Burrows-Wheeler Aligner (57) was utilized to 
perform reference genome alignment (hg19) with reads contained in paired FASTQ files. As the first post-alignment processing step, Picard (a collection of command-line tools for handling high-throughput sequencing data; broadinstitute. github.io/picard/) was utilized to identify and mark duplicate reads from BAM files. In the second post-alignment processing step, local read realignment was performed to correct for potential alignment errors around indels. Variant calls were generated using GATK HaplotypeCaller (gatk. broadinstitute.org/hc/en-us) (58) [which calls single-nucleotide polymorphisms (SNPs) and indels simultaneously via local de novo assembly of haplotypes in an active region] or UnifiedGenotyper (59) (which calls SNPs and indels on a per-locus basis) (60). A Gaussian mixture model was used to assign accurate confidence scores to each putative variant call, and SnpEff (pcingola.github.io/SnpEff/) (an open-source tool that annotates variants and predicts their effects on genes by using an interval forest approach) was utilized to add biological information for the variants (61). Rare variants with gnomAD minor allele frequency $<0.01$ were retained, and functional DNA changes impacting amino acid sequence and intron-exon junctions in the 26 known BBS genes (Table I) were prioritized for further analysis using the Integrated Genomics Viewer (software.broadinstitute.org/software/igv/home) (62). BBS12 c. $1063 \mathrm{C}>\mathrm{T}$; p.Arg $355^{*}$ was confirmed in the proband and available family members by PCR amplification with the following thermocycling conditions: Initial denaturation, $95^{\circ} \mathrm{C}$ for $5 \mathrm{~min}$; followed by 10 cycles of denaturation at $95^{\circ} \mathrm{C}$ for $30 \mathrm{sec}$, annealing at $66^{\circ} \mathrm{C}$ for $30 \mathrm{sec}$, and extension at $72^{\circ} \mathrm{C}$ for $30 \mathrm{sec}\left(-1^{\circ} \mathrm{C} /\right.$ cycle $)$; 40 cycles of denaturation at $95^{\circ} \mathrm{C}$ for $30 \mathrm{sec}$, annealing at $56^{\circ} \mathrm{C}$ for $30 \mathrm{sec}$, and extension at $72^{\circ} \mathrm{C}$ for $30 \mathrm{sec}$; and a final extension step at $72^{\circ} \mathrm{C}$ for $10 \mathrm{~min}$. The sequences of the primers used were: BBS12_PCR1 forward, 5'-TTGTGTGCAACAAGGCAAC-3' and reverse, 5'-TTCACT GAGCCGATTACCAAC-3'. This was followed by capillary sequencing using BigDye terminator 3.1 chemistry using an ABI 3730xl DNA Analyzer according to the manufacturer's protocols (Applied Biosystems; Thermo Fisher Scientific, Inc.).

The proband was the first daughter of a young (mother 17 years-old, father 20 years-old) and apparently healthy Romani couple. The family self-reported as non-consanguineous. The second daughter was reported to be healthy. The family history included Down's syndrome in a paternal cousin, as well as several ( $>3$ cases) familial cases of intellectual disability on the father's side of the family. The patient was born at 42 weeks by vaginal delivery after an uneventful pregnancy. The physical parameters at birth were within the expected normal range [weight, 3,070 g (70th percentile); length, $50 \mathrm{~cm}$ (30th percentile); the occipitofrontal circumference (OFC) was not provided]. The patient was admitted to the intensive care unit for $12 \mathrm{~h}$, needing incubator support due to the poor adaptation. Subsequently, the post-natal development progressed normally. Postaxial polydactyly was noted in all four limbs, and supernumerary digits were removed surgically at 8 months (Fig. 2). Psychomotor development was normal (the patient was able to sit at 6 months; walk without support at 14 months; said the first syllables at 6 months; and the first words at 12 months). The patient was evaluated at 6 years of age by a multidisciplinary team, including a pediatrician, child psychiatrist, child neurologist, psychologist, clinical geneticist and ophthalmologist.
A DM1569

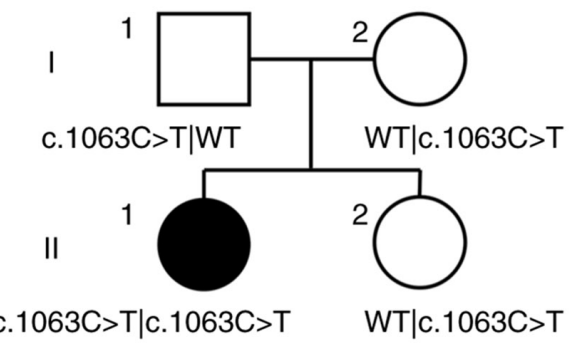

B

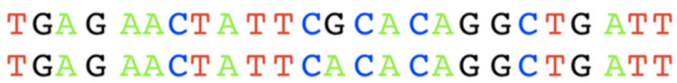

$\mathrm{I}-1$

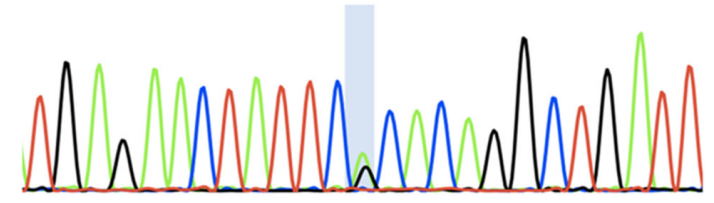

$\mathrm{I}-2$

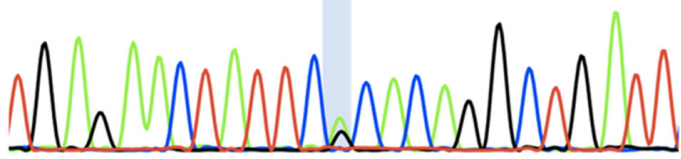

II-1

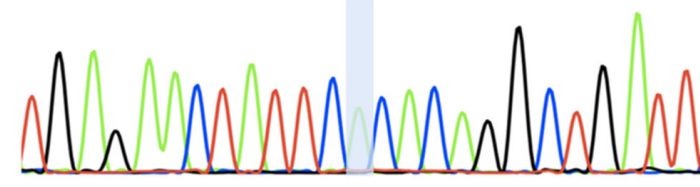

II-2

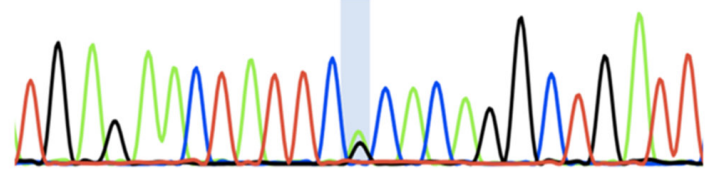

Figure 3. Pedigree and segregation analysis of BBS12 NM_152618.3: c.1063C $>$ T, p.Arg 355*. (A) Pedigree of the family. White shapes, unaffected; black shapes, affected; squares, males; circles, females. The genotype of the BBS variant are shown. (B) Chromatograms showing sequence traces flanking the $c .1063 \mathrm{C}>\mathrm{T}$ variant. Both parents are heterozygous and the proband is homozygous for the pathogenic change. WT, wild type; BBS, Bardet-Biedl syndrome.

Clinical workup revealed that she was obese [her weight was $52 \mathrm{~kg}$ (>7.5 standard deviations (SD) above the mean)]; she was of tall stature [her height was $128 \mathrm{~cm}(>2.5 \mathrm{SD}$ above the mean)]; and relative macrocephaly was identified [her OFC was $56 \mathrm{~cm}$ ( $>3.6 \mathrm{SD}$ above the mean)]. Several dysmorphic traits were also observed, namely a narrow forehead, a decreased bitemporal diameter, sparse eyebrow hypertelorism, long and smooth philtrum, large ears and full cheeks. Furthermore, oral/dental abnormalities were identified, including dysplastic teeth, a high-arched palate and digit anomalies, such as brachydactyly, conic fingers, partial cutaneous syndactyly of the second and third toes, and hypoplasia of the nails were also noted. An ophthalmological examination revealed retinal dystrophy; the patient's night vision was also very poor, and her daylight vision was weak (she frequently collides with objects while walking) as reported by her. However, specific measurements of visual acuity could not be obtained due to non-cooperation 
Table II. Clinical findings of the patients with BBS harboring the BBS12:c.1063C>T homozygous variant.

\begin{tabular}{|c|c|c|c|c|}
\hline Patient characteristics & Present case & Case \#1 and \#2 & Case \#3 & Case \#4 \\
\hline Reference & - & $(57)$ & $(62)$ & $(63)$ \\
\hline Additional genomic variants & - & - & - & BBS1:c.1016A $>\mathrm{T}$ \\
\hline Age at time of report & 7 years & NP & 5 months & NP \\
\hline Sex & Female & NP & Male & Female \\
\hline Ethnic background & Romani & Romani & NP & NP \\
\hline \multicolumn{5}{|l|}{ Phenotype } \\
\hline Retinitis pigmentosa & Yes & NP & No & Yes \\
\hline Obesity & $\begin{array}{l}\text { Yes (>6 standard } \\
\text { deviations) }\end{array}$ & NP & Yes (>97th percentile) & No \\
\hline Intellectual disability & $\begin{array}{l}\text { Severe (IQ 36) } \\
\text { (cognitive and language } \\
\text { impairment) }\end{array}$ & NP & No & $\begin{array}{l}\text { Yes (cognitive, } \\
\text { language and motor } \\
\text { impairment) }\end{array}$ \\
\hline Polydactyly & All limbs & NP & Feet & Feet \\
\hline $\begin{array}{l}\text { Genital anomalies/ } \\
\text { hypogonadism }\end{array}$ & $\begin{array}{l}\text { Yes (hypoplastic } \\
\text { genitalia) }\end{array}$ & NP & $\begin{array}{l}\text { Yes (small penis, } \\
\text { small testicles) }\end{array}$ & Yes (NS) \\
\hline $\begin{array}{l}\text { Kidney disfunction/ } \\
\text { anomaly }\end{array}$ & $\begin{array}{l}\text { Yes (elevated levels of } \\
\text { creatinine and urea) }\end{array}$ & NP & No & Yes (NS) \\
\hline Miscellaneous & $\begin{array}{l}\text { Severe behavioral } \\
\text { abnormalities, } \\
\text { hypercholesterolemia, } \\
\text { hypertension, } \\
\text { brachydactyly, } \\
\text { syndactyly of 2-3 toes }\end{array}$ & NP & $\begin{array}{l}\text { Heart anomaly, } \\
\text { brachydactyly, syndactyly } \\
\text { of 5-6 left toes }\end{array}$ & Hypercholesterolemia \\
\hline
\end{tabular}

and severe intellectual disability. The neurological evaluation revealed language impairment (echolalia, bradylalia, a limited vocabulary and the use of expressions that the patient had heard on television) and no sphincter control. Psychiatric and psychological workup revealed severe intellectual disability (IQ score 36), behavioral disturbances, including emotional instability, self-aggressiveness, addictive behavior towards the phone and television (the patient liked to listen to music, sing and dance), severe hyperkinesia and abnormal food behavior (the patient asked repeatedly for food). The patient knew her name and age, and could count up to 10; however, she could not recognize colors or play with a puzzle. Abdominal ultrasound revealed the presence of hypoplastic genitalia, although her liver and kidneys appeared normal. Likewise, electroencephalography and brain MRI investigations were unremarkable. Over the course of the last year (at 7 years of age) slightly elevated levels of cholesterol [5.4 mmol/1 (normal range $<5.2 \mathrm{mmol} / \mathrm{l}$ )], creatinine $[68 \mu \mathrm{mol} / 1$ (normal range $35-65 \mu \mathrm{mol} / \mathrm{l}$ )] and urea [8.4 mmol/1 (normal range $1.4-8.3 \mathrm{mmol} / \mathrm{l}$ )] were recorded for the patient, and she displayed several episodes of high blood pressure that responded well to treatment.

\section{Discussion}

In this case report, a homozygous BBS12 NM_152618.3: c. $1063 \mathrm{C}>\mathrm{T}$, p.Arg355* variant was identified using WES. This change was confirmed by Sanger sequencing and was shown to segregate with disease in the pedigree; both parents and the unaffected sibling were heterozygous carriers (Fig. 3). This variant has been reported previously in dbSNP (rs121918327; ncbi.nlm.nih.gov/snp/), and in ClinVar (VCV000001147.9; ncbi. nlm.nih.gov/clinvar/) as being pathogenic according to the American College of Medial Genetics and Genomics guidelines (63) (PVS1, PP3, PM2). The variant is a nonsense mutation that is predicted to result in a premature stop codon within the apical domain of the protein (64). Experimental validation remains necessary to determine whether $\mathrm{p}$.Arg $355^{*}$ produces an unstable protein that is targeted for degradation, or whether it generates a stable polypeptide with compromised function.

BBS12 (MIM 610683) is located on chromosome 4q27 and contains two exons, which code for a protein of 710 amino acids that belongs to a chaperonin-like complex, in addition to MKKS/BBS6 and BBS10 (41). The chaperonin-like complex, MKKS/BBS6-BBS10-BBS12, was initially considered to be vertebrate specific, and the proteins have similarity to the canonical type II chaperonins that are present in eukaryotic organisms (64-66). Subsequently, new evidence revealed that the proteins evolved earlier, due to the presence of several orthologs in ancient eukaryotes (67). Whereas canonical eukaryotic chaperonins utilize an ATP-specific hydrolytic site for protein folding, the rapidly evolved chaperonin-like proteins lost the ATPase hydrolytic site, but acquired novel functions, including the transduction of different morphogenetic signals from cilia $(64,67)$.

The three chaperonin-like proteins have been shown to be localized at the base of the cilium, in the pericentriolar region of the basal body and centrosome. They are required for initial assembly of the BBSome, and operate through stabilizing 
the BBS7 protein and subsequently recruiting BBS2 protein as an intermediary protein for the binding of a six prototypic chaperonin-containing tailless complex, which is responsible for completion of the folding process (27). Disruption of one of the chaperonin-like BBS genes leads to degradation of at least two subunits of the BBSome. The remaining BBSome proteins either stand as monomers or form aggregates with unspecified proteins (27).

As a consequence associated with this phenotype, it has been suggested that the deleterious variants in the MKKS/BBS6-BBS10-BBS12 complex may lead to a more severe phenotype and earlier onset of the disease compared with variants in the BBSome subunits $(68,69)$. This may be accounted for by the existence of an intermediary complex that manages to retain some residual function in spite of a BBSome component being impaired, whereas alteration of the chaperonin-like complex components serve to restrain the aggregation of any functional complex (28). There is also some evidence to suggest that visual impairment is most severe in cases associated with alterations in the chaperonin-like BBS genes, with similar effects observed for all three genes (68). Furthermore, cognitive impairment is highly prevalent in individuals with $B B S 12$ variants, whereas urogenital abnormalities are more common in those carrying $B B S 10$ pathogenic variants (69).

Four cases with BBS12 c. $1063 \mathrm{C}>\mathrm{T}$, p.Arg $355^{*}$, have been reported previously (Table II) $(64,70,71)$. In total, 3 of the 5 patients (including the presented case) reported are Romani; however, the ethnic backgrounds of the other 2 patients have not been provided, so it is not possible to conclude whether they share the same ethnicity. Interestingly, one of the patients reported previously is also Romanian, and although he is not located in the same geographic area as the current patient, the presence of a putative founder mutation cannot be excluded. Furthermore, the phenotypes of patients \#1 and \#2 were not reported. For the remaining 3 patients, some similarities have been observed: Genital anomalies were present in all cases. The other findings are variable, and may be explained either by the young age of patient \#3 at the time of study, given that certain symptoms occur later in life, or by an additional genomic variant in patient \#4 that may have influenced the phenotype. Even though they harbored the same variants, polydactyly was noted in all four limbs in the current patient, whereas in patient \#3 polydactyly was observed only in the feet. The heart anomaly described in patient \#3 was not present in the patient reported here. Therefore, further studies are required to elucidate the complex pathological mechanisms underpinning this highly heterogenous ciliopathy.

In conclusion, the present case report has provided novel evidence in terms of defining the phenotype associated with this rare variant in $B B S 12$.

\section{Acknowledgements}

Not applicable.

\section{Funding}

This study was funded by the US National Institutes of Health (grant nos. R01 HD042601, R01 DK072301 and
R01 GM121317). EED is the Ann Marie and Francis Klocke, MD Research Scholar.

\section{Availability of data and materials}

Due to constraints of participant consent, whole exome sequencing data are not posted to public databases, but we will make portions of the dataset available to researchers upon reasonable request.

\section{Authors' contributions}

IOF collected the data, wrote the manuscript, and prepared the figures and the tables. MBu and CB provided the clinical care of the patient. SK performed Sanger confirmation and segregation analysis. AS assisted with organization of clinical samples and data. LCB facilitated the initial preparation of samples. EED conducted the genetic testing and edited the manuscript. $\mathrm{MBa}$ designed the study, and revised the manuscript. All authors have read and approved the final manuscript. SK and EED confirm the authenticity of all the raw sequencing data.

\section{Ethics approval and consent to participate}

Willing family members were enrolled in the $\mathrm{PhD}$ research study approved by Institutional Board of University of Medicine and Pharmacy 'Carol Davila' Bucharest, (approval no. 29700, T.42; Oct 01, 2015), and all experiments conformed with the guidelines of the Declaration of Helsinki. The use of whole exome sequencing was approved by the Institutional Review Board of the Ann \& Robert H. Lurie Children's Hospital, Chicago (approval no. IRB 2019-3057, August 5, 2019).

\section{Patient consent for publication}

Written informed consent was obtained from legal guardians of the patient included in the study for genetic testing and publication of data and images, as well from all the other participants from whom samples were obtained.

\section{Competing interests}

The authors declare that they have no competing interests.

\section{References}

1. Zaghloul NA and Katsanis N: Mechanistic insights into Bardet-Biedl syndrome, a model ciliopathy. J Clin Invest 119: 428-437, 2009.

2. Kousi M, Soylemez O, Ozanturk A, Mourtzi N, Akle S, Jungreis I, Muller J, Cassa CA, Brand H, Mokry JA, et al: Evidence for secondary-variant genetic burden and non-random distribution across biological modules in a recessive ciliopathy. Nat Genet 52: $1145-1150,2020$

3. Focşa IO, Budișteanu M and Bălgrădean M: Clinical and genetic heterogeneity of primary ciliopathies (Review). Int J Mol Med 48: 176, 2021.

4. Forsythe E and Beales PL: Bardet-Biedl syndrome. Eur J Hum Genet 21: 8-13, 2013.

5. Beales PL, Elcioglu N, Woolf AS, Parker D and Flinter FA: New criteria for improved diagnosis of Bardet-Biedl syndrome: Results of a population survey. J Med Genet 36: 437-446, 1999.

6. Weihbrecht K, Goar WA, Pak T, Garrison JE, DeLuca AP, Stone EM, Scheetz TE and Sheffield VC: Keeping an eye on bardet-biedl syndrome: A Comprehensive review of the role of bardet-biedl syndrome genes in the eye. Med Res Arch: 5: 10.18103/mra.v5i9.1526, 2017. 
7. Forsythe E, Kenny J, Bacchelli $\mathrm{C}$ and Beales PL: Managing bardet-biedl syndrome-now and in the future. Front Pediatr 6: 23, 2018.

8. Imhoff O, Marion V, Stoetzel C, Durand M, Holder M, Sigaudy S, Sarda P, Hamel CP, Brandt C, Dollfus H and Moulin B: Bardet-Biedl syndrome: A study of the renal and cardiovascular phenotypes in a French cohort. Clin J Am Soc Nephrol 6: 22-29, 2011.

9. Mujahid S, Hunt KF, Cheah YS, Forsythe E, Hazlehurst JM, Sparks K, Mohammed S, Tomlinson JW, Amiel SA, Carroll PV, et al: The endocrine and metabolic characteristics of a large bardet-biedl syndrome clinic population. J Clin Endocrinol Metab 103: 1834-1841, 2018.

10. Kerr EN, Bhan A and Heon E: Exploration of the cognitive, adaptive and behavioral functioning of patients affected with Bardet-Biedl syndrome. Clin Genet 89: 426-433, 2016.

11. Forsyth RL and Gunay-Aygun M: Bardet-biedl syndrome overview. In: GeneReviews ${ }^{\circledR}$ [Internet]. Adam MP, Ardinger HH, Pagon RA, et al (eds). University of Washington, Seattle, WA, 1993.

12. Forsythe E, Sparks K, Best S, Borrows S, Hoskins B, Sabir A, Barrett T, Williams D, Mohammed S, Goldsmith D, et al: Risk factors for severe renal disease in bardet-biedl syndrome. J Am Soc Nephrol 28: 963-970, 2017.

13. Putoux A, Attie-Bitach T, Martinovic J and Gubler MC: Phenotypic variability of Bardet-Biedl syndrome: Focusing on the kidney. Pediatr Nephrol 27: 7-15, 2012.

14. Marchese E, Ruoppolo M, Perna A, Capasso G and Zacchia M: Exploring key challenges of understanding the pathogenesis of kidney disease in bardet-biedl syndrome. Kidney Int Rep 5: 1403-1415, 2020

15. Moore SJ, Green JS, Fan Y, Bhogal AK, Dicks E, Fernandez BA, Stefanelli M, Murphy C, Cramer BC, Dean JC, et al: Clinical and genetic epidemiology of Bardet-Biedl syndrome in Newfoundland: A 22-year prospective, population-based, cohort study. Am J Med Genet A 132A: 352-360, 2005.

16. Elbedour K, Zucker N, Zalzstein E, Barki Y and Carmi R: Cardiac abnormalities in the Bardet-Biedl syndrome: Echocardiographic studies of 22 patients. Am J Med Genet 52: 164-169, 1994

17. Branfield Day L, Quammie C, Héon E, Bhan A, Batmanabane V, Dai T and Kamath BM: Liver anomalies as a phenotype parameter of Bardet-Biedl syndrome. Clin Genet 89: 507-509, 2016.

18. Olson AJ, Krentz AD, Finta KM, Okorie UC and Haws RM: Thoraco-abdominal abnormalities in bardet-biedl syndrome: Situs inversus and heterotaxy. J Pediatr 204: 31-37, 2019.

19. Jin H, White SR, Shida T, Schulz S, Aguiar M, Gygi SP, Bazan JF and Nachury MV: The conserved Bardet-Biedl syndrome proteins assemble a coat that traffics membrane proteins to cilia Cell 141: 1208-1219, 2010.

20. Nachury MV, Loktev AV, Zhang Q, Westlake CJ, Peränen J Merdes A, Slusarski DC, Scheller RH, Bazan JF, Sheffield VC and Jackson PK: A core complex of BBS proteins cooperates with the GTPase Rab8 to promote ciliary membrane biogenesis. Cell 129: 1201-1213, 2007.

21. Lechtreck KF: IFT-cargo interactions and protein transport in cilia. Trends Biochem Sci 40: 765-778, 2015.

22. Bhogaraju S, Engel BD and Lorentzen E: Intraflagellar transport complex structure and cargo interactions. Cilia 2: 10, 2013.

23. Liew GM, Ye F, Nager AR, Murphy JP, Lee JS, Aguiar M, Breslow DK, Gygi SP and Nachury MV: The intraflagellar transport protein IFT27 promotes BBSome exit from cilia through the GTPase ARL6/BBS3. Dev Cell 31: 265-278, 2014.

24. Eguether T, San Agustin JT, Keady BT, Jonassen JA, Liang Y, Francis R, Tobita K, Johnson CA, Abdelhamed ZA, Lo CW and Pazour GJ: IFT27 links the BBSome to IFT for maintenance of the ciliary signaling compartment. Dev Cell 31: 279-290, 2014

25. Brown JM, Cochran DA, Craige B, Kubo T and Witman GB: Assembly of IFT trains at the ciliary base depends on IFT74 Curr Biol 25: 1583-1593, 2015.

26. Bujakowska KM, Zhang Q, Siemiatkowska AM, Liu Q, Place E, Falk MJ, Consugar M, Lancelot ME, Antonio A, Lonjou C, et al: Mutations in IFT172 cause isolated retinal degeneration and Bardet-Biedl syndrome. Hum Mol Genet 24: 230-242, 2015.

27. Seo S, Baye LM, Schulz NP, Beck JS, Zhang Q, Slusarski DC and Sheffield VC: BBS6, BBS10, and BBS12 form a complex with $\mathrm{CCT} / \mathrm{TR}$ iC family chaperonins and mediate BBSome assembly. Proc Natl Acad Sci USA 107: 1488-1493, 2010.
28. Alvarez-Satta M,Castro-Sanchez S and Valverde D: Bardet-biedl syndrome as a chaperonopathy: Dissecting the major role of chaperonin-like BBS proteins (BBS6-BBS10-BBS12). Front Mol Biosci 4: 55, 2017.

29. Dawe HR, Smith UM,Cullinane AR, GerrelliD, Cox P, Badano JL, Blair-Reid S, Sriram N, Katsanis N, Attie-Bitach T, et al: The Meckel-gruber syndrome proteins MKS1 and meckelin interact and are required for primary cilium formation. Hum Mol Genet 16: 173-186, 2007.

30. Barbelanne M, Hossain D, Chan DP, Peranen J and Tsang WY: Nephrocystin proteins NPHP5 and Cep290 regulate BBSome integrity, ciliary trafficking and cargo delivery. Hum Mol Genet 24: 2185-2200, 2015.

31. Williams CL, Li C, Kida K, Inglis PN, Mohan S, Semenec L, Bialas NJ, Stupay RM, Chen N, Blacque OE, et al: MKS and NPHP modules cooperate to establish basal body/transition zone membrane associations and ciliary gate function during ciliogenesis. J Cell Biol 192: 1023-1041, 2011.

32. Marion V, Stutzmann F, Gerard M, De Melo C, Schaefer E, Claussmann A, Hellé S, Delague V, Souied E, Barrey C, et al: Exome sequencing identifies mutations in LZTFL1, a BBSome and smoothened trafficking regulator, in a family with Bardet-Biedl syndrome with situs inversus and insertional polydactyly. J Med Genet 49: 317-321, 2012.

33. Seo S, Zhang Q, Bugge K, Breslow DK, Searby CC, Nachury MV and Sheffield VC: A novel protein LZTFL1 regulates ciliary trafficking of the BBSome and Smoothened. PLoS Genet 7: e1002358, 2011.

34. Das A, Qian J and Tsang WY: USP9X counteracts differential ubiquitination of NPHP5 by MARCH7 and BBS11 to regulate ciliogenesis. PLoS Genet 13: e1006791, 2017.

35. Heon E, Kim G, Qin S, Garrison JE, Tavares E, Vincent A, Nuangchamnong N, Scott CA, Slusarski DC and Sheffield VC: Mutations in C8ORF37 cause Bardet Biedl syndrome (BBS21). Hum Mol Genet 25: 2283-2294, 2016.

36. Lindstrand A, Davis EE, Carvalho CM, Pehlivan D, Willer JR, Tsai IC, Ramanathan S, Zuppan C, Sabo A, Muzny D, et al: Recurrent CNVs and SNVs at the NPHP1 locus contribute pathogenic alleles to Bardet-Biedl syndrome. Am J Hum Genet 94: 745-754, 2014.

37. Morisada N, Hamada R, Miura K, Ye MJ, Nozu K, Hattori M and Iijima K: Bardet-Biedl syndrome in two unrelated patients with identical compound heterozygous SCLT1 mutations. CEN Case Rep 9: 260-265, 2020

38. Shamseldin HE, Shaheen R, Ewida N, Bubshait DK, Alkuraya H, Almardawi E, Howaidi A, Sabr Y, Abdalla EM, Alfaifi AY, et al: The morbid genome of ciliopathies: An update. Genet Med 22: 1051-1060, 2020

39. Yang TT, Chong WM, Wang WJ, Mazo G, Tanos B, Chen Z, Tran TMN, Chen YD, Weng RR, Huang CE, et al: Super-resolution architecture of mammalian centriole distal appendages reveals distinct blade and matrix functional components. Nat Commun 9: 2023, 2018.

40. Wormser O, Gradstein L, Yogev Y, Perez Y, Kadir R, Goliand I, Sadka Y, El Riati S, Flusser H, Nachmias D, et al: SCAPER localizes to primary cilia and its mutation affects cilia length, causing Bardet-Biedl syndrome. Eur J Hum Genet 27: 928-940, 2019.

41. Khan SA, Muhammad N, Khan MA, Kamal A, Rehman ZU and Khan S: Genetics of human Bardet-Biedl syndrome, an updates. Clin Genet 90: 3-15, 2016.

42. Niederlova V, Modrak M, Tsyklauri O, Huranova M and Stepanek O: Meta-analysis of genotype-phenotype associations in Bardet-Biedl syndrome uncovers differences among causative genes. Hum mutat 40: 2068-2087, 2019

43. M'Hamdi O, Ouertani I, Maazoul F and Chaabouni-Bouhamed $\mathrm{H}$ Prevalence of bardet-biedl syndrome in tunisia. J Community Genet 2: 97-99, 2011

44. Farag TI and Teebi AS: High incidence of Bardet Biedl syndrome among the Bedouin. Clin Genet 36: 463-464, 1989.

45. Farag TI and Teebi AS: Bardet-Biedl and laurence-moon syndromes in a mixed arab population. Clin Genet 33: 78-82, 1988.

46. Abu Safieh L, Aldahmesh MA, Shamseldin H, Hashem M, Shaheen R, Alkuraya H, Al Hazzaa SA, Al-Rajhi A and Alkuraya FS: Clinical and molecular characterisation of Bardet-Biedl syndrome in consanguineous populations: The power of homozygosity mapping. J Med Genet 47: 236-241, 2010.

47. Sathya Priya C, Sen P, Umashankar V, Gupta N, Kabra M, Kumaramanickavel G, Stoetzel C, Dollfus H and Sripriya S: Mutation spectrum in BBS genes guided by homozygosity mapping in an Indian cohort. Clin Genet 87: 161-166, 2015. 
48. Katsanis N, Eichers ER, Ansley SJ, Lewis RA, Kayserili H, Hoskins BE, Scambler PJ, Beales PL and Lupski JR: BBS4 is a minor contributor to Bardet-Biedl syndrome and may also participate in triallelic inheritance. Am J Hum Genet 71: 22-29, 2002.

49. Katsanis N: The oligogenic properties of Bardet-Biedl syndrome. Hum Mol Genet 13: R65-R71, 2004.

50. Katsanis N, Ansley SJ, Badano JL, Eichers ER, Lewis RA, Hoskins BE, Scambler PJ, Davidson WS, Beales PL and Lupski JR: Triallelic inheritance in Bardet-Biedl syndrome, a Mendelian recessive disorder. Science 293: 2256-2259, 2001.

51. Davis EE, Zhang Q, Liu Q, Diplas BH, Davey LM, Hartley J, Stoetzel C, Szymanska K, Ramaswami G, Logan CV, et al: TTC21B contributes both causal and modifying alleles across the ciliopathy spectrum. Nat Genet 43: 189-196, 2011.

52. Badano JL, Leitch CC, Ansley SJ, May-Simera H, Lawson S, Lewis RA, Beales PL, Dietz HC, Fisher S and Katsanis N: Dissection of epistasis in oligogenic Bardet-Biedl syndrome. Nature 439: 326-330, 2006.

53. Lindstrand A, Frangakis S, Carvalho CM, Richardson EB McFadden KA, Willer JR, Pehlivan D, Liu P, Pediaditakis IL, Sabo A, et al: Copy-number variation contributes to the mutational load of bardet-biedl syndrome. Am J Hum Genet 99: 318-336, 2016

54. Delvallée C, Nicaise S, Antin M, Leuvrey AS, Nourisson E, Leitch CC, Kellaris G, Stoetzel C, Geoffroy V, Scheidecker S, et al: A BBS1 SVA F retrotransposon insertion is a frequent cause of Bardet-Biedl syndrome. Clin Genet 99: 318-324, 2021.

55. Shaheen R, Szymanska K, Basu B, Patel N, Ewida N, Faqeih E, Al Hashem A, Derar N, Alsharif H, Aldahmesh MA, et al: Characterizing the morbid genome of ciliopathies. Genome Biol 17: 242, 2016.

56. World Medical Association Declaration of Helsinki: Ethical principles for medical research involving human subjects. JAMA 310: 2191-2194, 2013.

57. Li H and Durbin R: Fast and accurate short read alignment with Burrows-Wheeler transform. Bioinformatics 25: 1754-1760, 2009.

58. Poplin R, Ruano-Rubio V, DePristo M, Fennell TJ, Carneiro MO, Van der Auwera GA, Kling DE, Gauthier LD, Levy-Moonshine A, Roazen D, et al: Scaling accurate genetic variant discovery to tens of thousands of samples. bioRxiv: doi: https://doi. org/10.1101/201178.

59. DePristo MA, Banks E, Poplin R, Garimella KV, Maguire JR, Hartl C, Philippakis AA, del Angel G, Rivas MA, Hanna M, et al: A framework for variation discovery and genotyping using next-generation DNA sequencing data. Nat Genet 43: 491-498, 2011.

60. McKenna A, Hanna M, Banks E, Sivachenko A, Cibulskis K, Kernytsky A, Garimella K, Altshuler D, Gabriel S, Daly M and DePristo MA: The Genome Analysis Toolkit: A MapReduce framework for analyzing next-generation DNA sequencing data. Genome Res 20: 1297-1303, 2010.
61. Cingolani P, Platts A, Wang le L, Coon M, Nguyen T, Wang L, Land SJ, Lu X and Ruden DM: A program for annotating and predicting the effects of single nucleotide polymorphisms, SnpEff: SNPs in the genome of Drosophila melanogaster strain w1118; iso-2; iso-3. Fly (Austin) 6: 80-92, 2012.

62. Robinson JT, Thorvaldsdóttir H, Winckler W, Guttman M, Lander ES, Getz G and Mesirov JP: Integrative genomics viewer. Nat Biotechnol 29: 24-26, 2011.

63. Richards S, Aziz N, Bale S, Bick D, Das S, Gastier-Foster J, Grody WW, Hegde M, Lyon E, Spector E, et al: Standards and guidelines for the interpretation of sequence variants: A joint consensus recommendation of the American College of Medical Genetics and Genomics and the Association for Molecular Pathology. Genet Med 17: 405-424, 2015.

64. Stoetzel C, Muller J, Laurier V, Davis EE, Zaghloul NA, Vicaire S, Jacquelin C, Plewniak F, Leitch CC, Sarda P, et al: Identification of a novel BBS gene (BBS12) highlights the major role of a vertebrate-specific branch of chaperonin-related proteins in Bardet-Biedl syndrome. Am J Hum Genet 80: 1-11, 2007.

65. Katsanis N, Beales PL, Woods MO, Lewis RA, Green JS, Parfrey PS, Ansley SJ, Davidson WS and Lupski JR: Mutations in MKKS cause obesity, retinal dystrophy and renal malformations associated with Bardet-Biedl syndrome. Nat Genet 26: 67-70, 2000.

66. Stoetzel C, Laurier V, Davis EE, Muller J, Rix S, Badano JL, Leitch CC, Salem N, Chouery E, Corbani S, et al: BBS10 encodes a vertebrate-specific chaperonin-like protein and is a major BBS locus. Nat Genet 38: 521-524, 2006.

67. Mukherjee K and Brocchieri L: Ancient origin of chaperonin gene paralogs involved in ciliopathies. J Phylogenetics Evol Biol 1: 107, 2013

68. Billingsley G, Bin J, Fieggen KJ, Duncan JL, Gerth C, Ogata K, Wodak SS, Traboulsi EI, Fishman GA, Paterson A, et al: Mutations in chaperonin-like BBS genes are a major contributor to disease development in a multiethnic Bardet-Biedl syndrome patient population. J Med Genet 47: 453-463, 2010.

69. Castro-Sánchez S, Álvarez-Satta M, Cortón M, Guillén E, Ayuso $\mathrm{C}$ and Valverde D: Exploring genotype-phenotype relationships in Bardet-Biedl syndrome families. J Med Genet 52: 503-513, 2015.

70. Iurian SI, Arts H, Brunner H and Fintina D: Bardet-biedl Syndrome-case presentation. Romanian J Pediatrics 64: 289-292, 2015.

71. Manara E, Paolacci S, D'Esposito F, Abeshi A, Ziccardi L, Falsini B, Colombo L, Iarossi G, Pilotta A, Boccone L, et al: Mutation profile of BBS genes in patients with Bardet-Biedl syndrome: An Italian study. Ital J Pediatr 45: 72, 2019. International (CC BY-NC-ND 4.0) License. 